\title{
Expression of phospholipase A2 receptor in primary cultured podocytes derived from dog kidneys
}

\author{
Go SUGAHARA ${ }^{1)}$, Junichi KAMIIE ${ }^{1)}$, Ryosuke KOBAYASHI ${ }^{1)}$, Takayuki MINESHIGE ${ }^{1)}$ and Kinji SHIROTA ${ }^{1) *}$ \\ ${ }^{1)}$ Laboratory of Veterinary Pathology, School of Veterinary Medicine, Azabu University, 1-17-71 Fuchinobe, Chuo-ku, Sagamihara, \\ Kanagawa 252-5201, Japan
}

(Received 24 December 2015/Accepted 23 January 2016/Published online in J-STAGE 6 February 2016)

ABSTRACT. Phospholipase A2 receptor $\left(\mathrm{PLA}_{2} \mathrm{R}\right)$ expressed in human podocytes has been highlighted as a causative autoantigen of human idiopathic membranous nephropathy. However, its expression was found to be minimal or absent in murine and rat podocytes. In this study, immunofluorescence revealed the expression of $\mathrm{PLA}_{2} \mathrm{R}$ in the glomerular podocytes in the kidney tissue sections of dogs. We then attempted to culture canine podocytes and investigate the expression of $\mathrm{PLA}_{2} \mathrm{R}$ in these cells. Glomeruli were isolated from dog kidneys and cultured to obtain podocytes using nylon mesh-based isolation method as followed for isolating rat podocytes. The cultured cells expressed PLA $\mathrm{R}$ mRNA and protein in addition to other podocyte markers (synaptopodin, podocin and nephrin). These results indicate that the canine podocytes express PLA $_{2} R$.

KEY WORDS: canine, glomerulus, kidney, phospholipase A2 receptor, podocyte

doi: 10.1292/jvms.15-0722; J. Vet. Med. Sci. 78(5): 895-899, 2016

Phospholipase $\mathrm{A}_{2}$ receptor $\left(\mathrm{PLA}_{2} \mathrm{R}\right)$ is a type I transmembrane glycoprotein related to the C-type animal lectin family [8] and is reported to mediate various biological processes via secretory $\mathrm{PLA}_{2}$ stimulation in various cells and tissues $[5,7]$. Recently, the expression of $\mathrm{PLA}_{2} \mathrm{R}$ in glomerular podocytes of the human kidney was demonstrated, and anti$\mathrm{PLA}_{2} \mathrm{R}$ autoantibodies were discovered in the majority of patients with idiopathic membranous nephropathy (MN) [1], a major cause of nephrotic disease in humans. Subsequent studies also reported an association between human idiopathic $\mathrm{MN}$ and $\mathrm{PLA}_{2} \mathrm{R}$, with the latter as a causative antigen [9-11]. However, its expression was found to be minimal or absent in mice and rats $[2,3,17]$. To date, a suitable animal model for human idiopathic $\mathrm{MN}$ induced by autoantibodies against $\mathrm{PLA}_{2} \mathrm{R}$ has not been established. For this reason, the function of this receptor in podocytes and whether the circulating autoantibodies actually bind to $\mathrm{PLA}_{2} \mathrm{R}$ on podocytes remain unclear. Therefore, the development of a suitable animal model is critical to understand the pathogenesis of human idiopathic $\mathrm{MN}$.

In dogs, $\mathrm{MN}$ is a major spontaneous glomerular disease, and its histopathological and clinical characteristics are analogous to human idiopathic $\mathrm{MN}[4,13]$. However, there are no reports describing the expression of $\mathrm{PLA}_{2} \mathrm{R}$ in canine podocytes. In veterinary medicine, several researchers have investigated canine glomeruli using tissue specimens and showed the expression of some podocyte-specific proteins $[12,16]$. However, there has been no in vitro research using

*Correspondence to: Shirota, K., Laboratory of Veterinary Pathology, Azabu University, 1-17-71 Fuchinobe, chuo-ku, Sagamihara, Kanagawa 252-5201, Japan. e-mail: shirota@azabu-u.ac.jp (C)2016 The Japanese Society of Veterinary Science

This is an open-access article distributed under the terms of the Creative Commons Attribution Non-Commercial No Derivatives (by-nc-nd) License $<$ http://creativecommons.org/licenses/by-nc-nd/4.0/>. canine cultured glomerular podocytes, because of the lack of a standard culture protocol for canine podocytes.

Here, we detected the expression of $\mathrm{PLA}_{2} \mathrm{R}$ in the renal glomerular podocytes in the tissue sections of dogs by immunofluorescence (IF). We then established a method of primary culture for canine podocytes and comfirmed the expression of $\mathrm{PLA}_{2} \mathrm{R}$, a candidate autoantigen for human idiopathic $\mathrm{MN}$, in primary cultured podocytes.

Renal tissues were obtained from three 12-month-old male beagles. All dogs were purchased from a laboratory animal breeding and supply company (Kitayama Labes Co., Ltd., Nagano, Japan) and were confirmed to be healthy by physical examination. The animals were used for clinical education and euthanized in accordance with the guidelines approved by the Animal Research Committee of Azabu University (No. 100408-3).

The unilateral kidneys were dissected from the dogs immediately after euthanasia as described below, fixed in $10 \%$ neutral buffered formalin, processed routinely and embedded in paraffin wax. The kidneys of the dogs were confirmed to be histologically normal by hematoxylin and eosin stain and periodic acid-Schiff reaction.

The method used for the primary culture of podocytes was based on a method for rat kidneys [15]. A 21-gauge butterfly needle was inserted into the artery of the other kidney immediately removed after euthanasia using an excess amount of pentobarbital (over $50 \mathrm{mg} / \mathrm{kg}$ body weight, intravenous injection) under inhalation anesthesia with $2 \%$ isoflurane, and the kidney was perfused with $20 \mathrm{ml}$ phosphate buffered saline (PBS: $\mathrm{pH} 7.2,0.01 \mathrm{M})$ and $30 \mathrm{~m} l$ PBS containing $36 \mathrm{mg}$ of iron powder ( $\varphi 6 \mu \mathrm{m}$; Wako, Tokyo, Japan). Renal cortical tissue was then cut into 1-2 mm cubes in Hanks' balanced salt solution (HBSS; Invitrogen Life Technologies, Carlsbad, CA, U.S.A.). The tissues were digested in HBSS containing $1 \mathrm{mg} / \mathrm{m} l$ collagenase A (Roche Diagnostics $\mathrm{GmbH}$, Mannheim, Germany) and $0.2 \mathrm{mg} / \mathrm{m} l$ deoxyribo- 
nuclease I (Roche Diagnostics $\mathrm{GmbH}$ ) at $37^{\circ} \mathrm{C}$ for $60 \mathrm{~min}$ with gentle agitation. The collagenase-digested tissues were gently pressed through a $250-\mu \mathrm{m}$ tissue strainer (Thermo Fisher Scientific, Basingstoke, U.K.). Glomeruli containing iron powder in the tissue suspension were gathered using a magnetic particle concentrator (Dynal AS, Oslo, Norway) and washed at least four times with PBS. Finally, collected glomeruli were suspended in a suitable amount (approximately $12 \mathrm{~m} l$ ) of PBS, and the suspension was poured onto a 70- $\mu \mathrm{m}$ cell strainer (BD Biosciences, Stockholm, Sweden); the glomeruli remaining on the cell strainer were carefully collected. During the procedure, kidney tissues were maintained at $4^{\circ} \mathrm{C}$, except for collagenase digestion.

Isolated glomeruli were seeded onto type I collagencoated culture dishes or glass coverslips (Asahi techno glass, Tokyo, Japan) in Dulbecco's modified Eagle's medium: nutrient mixture F-12 (D-MEM:F-12, 1:1; Invitrogen) containing 5\% fetal bovine serum (FBS; Hana-nesco Bio., Tokyo, Japan) supplemented with $0.5 \%$ insulin-transferrinselenium-A (ITS-A) liquid media supplement (Invitrogen) and $1 \%$ antibiotic-antimycotic liquid (Invitrogen). IF was performed after incubation at $37^{\circ} \mathrm{C}$ in a humidified incubator with $5 \% \mathrm{CO}_{2}$ for three days.

For subculture of primary cultured podocytes, the cellular outgrowths obtained following three days of incubation were detached using a trypsin ethylenediaminetetraacetic acid (EDTA) solution containing 2 g Difco ${ }^{\mathrm{TM}}$ Trypsin 250 (BD Biosciences) and $0.4 \mathrm{mg}$ EDTA, disodium salt, dihydrate in $200 \mathrm{~m} l$ of $0.01 \mathrm{M} \mathrm{PBS}, \mathrm{pH} 7.2$, passed through a $40-\mu \mathrm{m}$ sieve (BD Biosciences) to remove the remaining glomerular cores, and the filtered cells were gathered by centrifugation at $1,000 \times \mathrm{g}$. The obtained cells were then cultured on collagen I-coated dishes for 1 day and processed for reverse transcriptase polymerase chain reaction (RT-PCR) or Western blotting (WB) preparation.

The primary antibodies used in this study were the following reagents: mouse anti- $\mathrm{PLA}_{2} \mathrm{R}$ (Atlas Antibodies $\mathrm{AB}$, Stockholm, Sweden, 1 in 100 dilution for IF and 1 in 700 for WB), rabbit anti-human podocin (Sigma, St. Louis, MO, U.S.A.), goat anti-synaptopodin (Santa Cruz Biotechnology, Santa Cruz, CA, U.S.A.; 1 in 100 dilution for IF) and rabbit anti-canine nephrin (Kobayashi et al. 2012 [16], 1 in 50 dilution for IF).

For IF, the dewaxed kidney sections were pretreated with citrate buffer $(\mathrm{pH} 6.0)$ at $121^{\circ} \mathrm{C}$ for $15 \mathrm{~min}$ in an autoclave before incubation with anti-PLA ${ }_{2} \mathrm{R}$ antibody. The cultured podocytes were fixed in methanol for $5 \mathrm{~min}$ at $4{ }^{\circ} \mathrm{C}\left(\mathrm{PLA}_{2} \mathrm{R}\right.$, podocin and nephrin) or in $4 \%$ paraformaldehyde at $4{ }^{\circ} \mathrm{C}$ (synaptopodin). The cultured cells were treated with $0.1 \%$ Triton X-100 in PBS for 5 min after fixation by paraformaldehyde. Non-specific protein binding to the tissue sections and cultured cells was blocked with $4 \%$ Block Ace ${ }^{\mathrm{TM}}$ (Yukijirushi, Sapporo, Japan) for $10 \mathrm{~min}$ at room temperature, and these specimens were then incubated with the primary antibodies at $4{ }^{\circ} \mathrm{C}$ overnight. After washing with PBS, the specimens were incubated with secondary antibodies for $1 \mathrm{hr}$ at room temperature. One of the following secondary antibodies was used: Alexa Fluor 488-conjugated goat anti- rabbit IgG and Alexa Fluor 568-conjugated rabbit anti-goat IgG (Invitrogen; 1 in 500 dilution). Next, the specimens were washed with PBS; thereafter, they were counterstained and mounted with Vectashield mounting medium containing 4,'6'-diaminido-2-phenylindole (DAPI; Vector Laboratories, Burlingame, CA, U.S.A.). Images were obtained using a FSX100 fluorescence microscope (OLYMPUS, Tokyo, Japan).

For RT-PCR, total RNA was extracted from subcultured podocytes using the RNeasy Plus Micro Kit (Qiagen, Hilden, Germany). First-strand cDNA was obtained from total RNA using a Sensiscript RT kit (Qiagen) with random primers (Invitrogen) in the presence of RNasin ribonuclease inhibitor (Promega, Madison, WI, U.S.A.). The primer sequences were designed based on the predicted mRNA sequences of Canis lupus familiaris nephrosis 1, congenital, Finnish type (nephrin) (NPHS1) (NCBI database, accession number: XM_541685), Canis lupus familiaris nephrosis 2, idiopathic, steroid-resistant (podocin) (NPHS2) (XM_547443.2), Canis lupus familiaris synaptopodin (SYNPO) (XM_536465.5) and Canis lupus familiaris phospholipase $\overline{\mathrm{A}} 2$ receptor 1 (PLA2R1) (XM_545489.4). The primer sequences were as follows: NPHS1: forward, TCGGGTAGCAGGAAACTTGG; reverse, AAGCCACCTCCCAGAAGAGT; NPHS2: forward, CAAAGTGCGGGTGATCGCT; reverse, GGCAACCAAAGGAAGTGCAG; SYNPO: forward, ACCCCATGGACTCAACGAAG; reverse, GGCCCAACGCTGGTTTCTG; PLA2R1: forward, ACAGGAGAAAACGGAGCAGG; reverse, ACTCCCAAGAGCCAGCATTC; canine glyceraldehyde-3-phosphate dehydrogenase (GAP$D H$ ): forward, CTGAACGGGAAGCTCACTGG; reverse, GTCGAAGGTGGAAGAGTGGG. Amplification of canine $G A P D H$ was used as a housekeeper. PCR reactions using KOD FX Neo (Toyobo, Osaka, Japan) were performed as follows: denaturation at $94^{\circ} \mathrm{C}$ for 2 min; 40 cycles of denaturation at $98^{\circ} \mathrm{C}$ for $10 \mathrm{sec}$, annealing at $64^{\circ} \mathrm{C}$ for $30 \mathrm{sec}$ and extension at $68^{\circ} \mathrm{C}$ for $30 \mathrm{sec}$; and a final extension step at $68^{\circ} \mathrm{C}$ for $30 \mathrm{sec}$.

For WB, the cultured podocytes were lysed in RIPA buffer [consisting of $0.1 \%$ sodium dodecyl sulfate (SDS), $1 \%$ $\mathrm{NP}-40,150 \mathrm{mM} \mathrm{NaCl}$ and $0.5 \%$ sodium deoxycholate in $50 \mathrm{mM}$ Tris-HCl, pH 7.4] with Protease Inhibitor Cocktail Set I (Wako, Osaka, Japan), and protein concentrations were assayed using the Lowry method (DC Protein Assay, BioRad, Hercules, CA, U.S.A.). For SDS-polyacrylamide gel electrophoresis (SDS-PAGE), the samples were mixed with an equal volume of sample buffer containing 10\% beta-mercaptoethanol (5\% final concentration) and then boiled for $5 \mathrm{~min}$. Proteins (10 $\mu \mathrm{g} /$ lane) were run on $10 \%$ polyacrylamide slab gels and transferred to polyvinylidene fluoride membranes. The membranes were blocked with $10 \%$ skimmed milk in PBS with $0.1 \%$ Tween 20 for $1 \mathrm{hr}$ at room temperature and incubated overnight at $4{ }^{\circ} \mathrm{C}$ with the primary antibodies diluted in Immuno-enhancer Reagent A (Wako). After washing, the membranes were incubated with a horseradish peroxidase-conjugated goat anti-mouse IgG antibody (Dako Cytomation, Glostrup, Denmark; 1 in 2,000 dilution) diluted in Immuno-enhancer Reagent B (Wako) for 
$1 \mathrm{hr}$ at room temperature. Immunoreactivity was visualized using Luminata ${ }^{\mathrm{TM}}$ Forte Western HRP Substrate (Millipore, Temicula, CA, U.S.A.) and detected using an LAS4000 (GE Healthcare Japan Co., Ltd., Tokyo, Japan).

Using IF for renal tissue sections, the expression of $\mathrm{PLA}_{2} \mathrm{R}$ was observed in the podocytes cell body and cell processes in the glomeruli as well as parietal epithelial cells (PECs) (Fig. 1).

A number of decapsulated glomeruli were collected from cortical tissue. However, a low rate of blood vessel and tubular contamination was observed $(3.3 \pm 1.5 \%$; $n=3)$. Cellular growth of podocytes from isolated glomeruli was first detected within 2 days and became prominent by 3-4 days in culture (Fig. 2). The podocyte morphology was irregular, often exhibiting arborization with long cytoplasmic processes and multinucleation. Their morphology was identical to that of primary cultured rat podocytes described in previous reports $[15,19]$. These cultured cells showed distinct expression of the podocyte-specific proteins-nephrin, podocin and synaptopodin (Fig. 3A). Synaptopodin exhibited a stress fiber-like appearance and cross striation. The cultured cells expressed nephrin and podocin in the cytoplasm and mar-

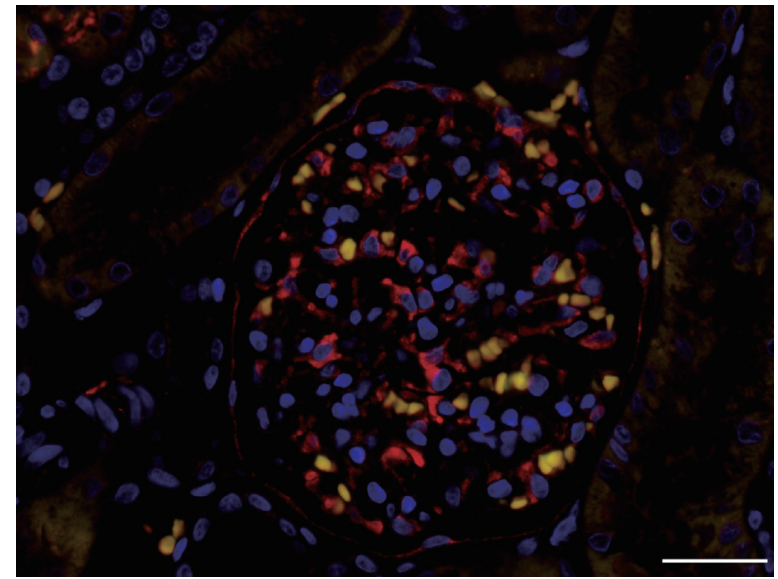

Fig. 1. Expression of phospholipase $\mathrm{A} 2$ receptor $\left(\mathrm{PLA}_{2} \mathrm{R}\right)$ in the canine glomerulus. The expression of $\mathrm{PLA}_{2} \mathrm{R}$ (red) was mainly observed in podocytes cell body and cell processes and also in parietal epithelial cells. Intrinsic fluorescence of red blood cells was demonstrated as yellow. Bar $=30 \mu \mathrm{m}$.
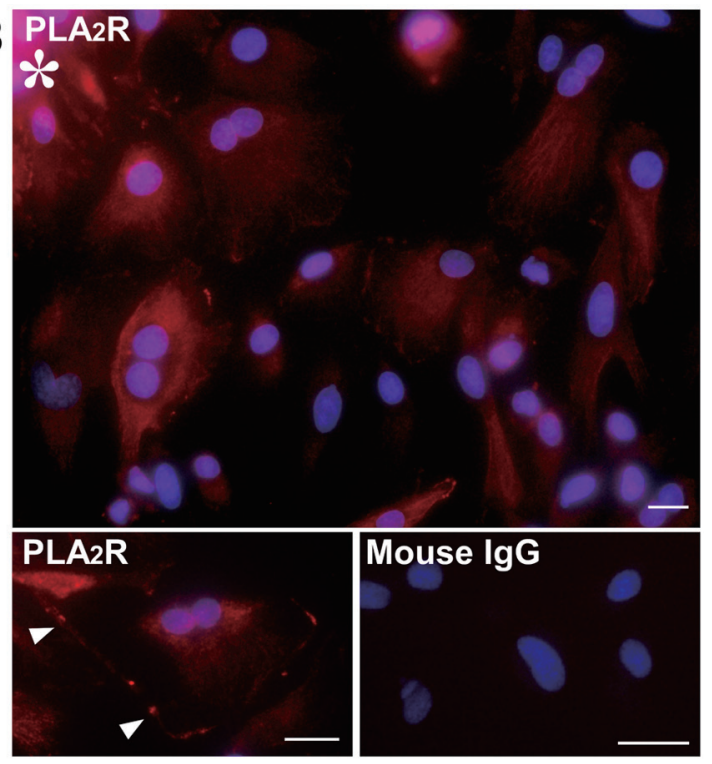

D

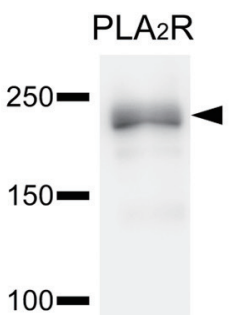

Fig. 3. Expression of phospholipase $\mathrm{A}_{2}$ receptor $\left(\mathrm{PLA}_{2} \mathrm{R}\right)$ and podocyte markers in primary cultured canine podocytes. Immunofluorescence for podocyte-specific proteins (synaptopodin, podocin and nephrin) $(\mathrm{A})$ and $P L \mathrm{~A}_{2} \mathrm{R}(\mathrm{B})$, reverse transcriptase polymerase chain reaction (RT-PCR) for podocyte-specific markers (NPHS2, SYNPO and NPHS1), PLA2R1 and GAPDH(C) and Western blotting for $\mathrm{PLA}_{2} \mathrm{R}$ protein (D) in canine primary cultured podocytes. Mouse IgG: negative control. Arrowheads: expression on marginal region. Asterisk: Isolated glomerulus. Bar $=25 \mu \mathrm{m}$. 

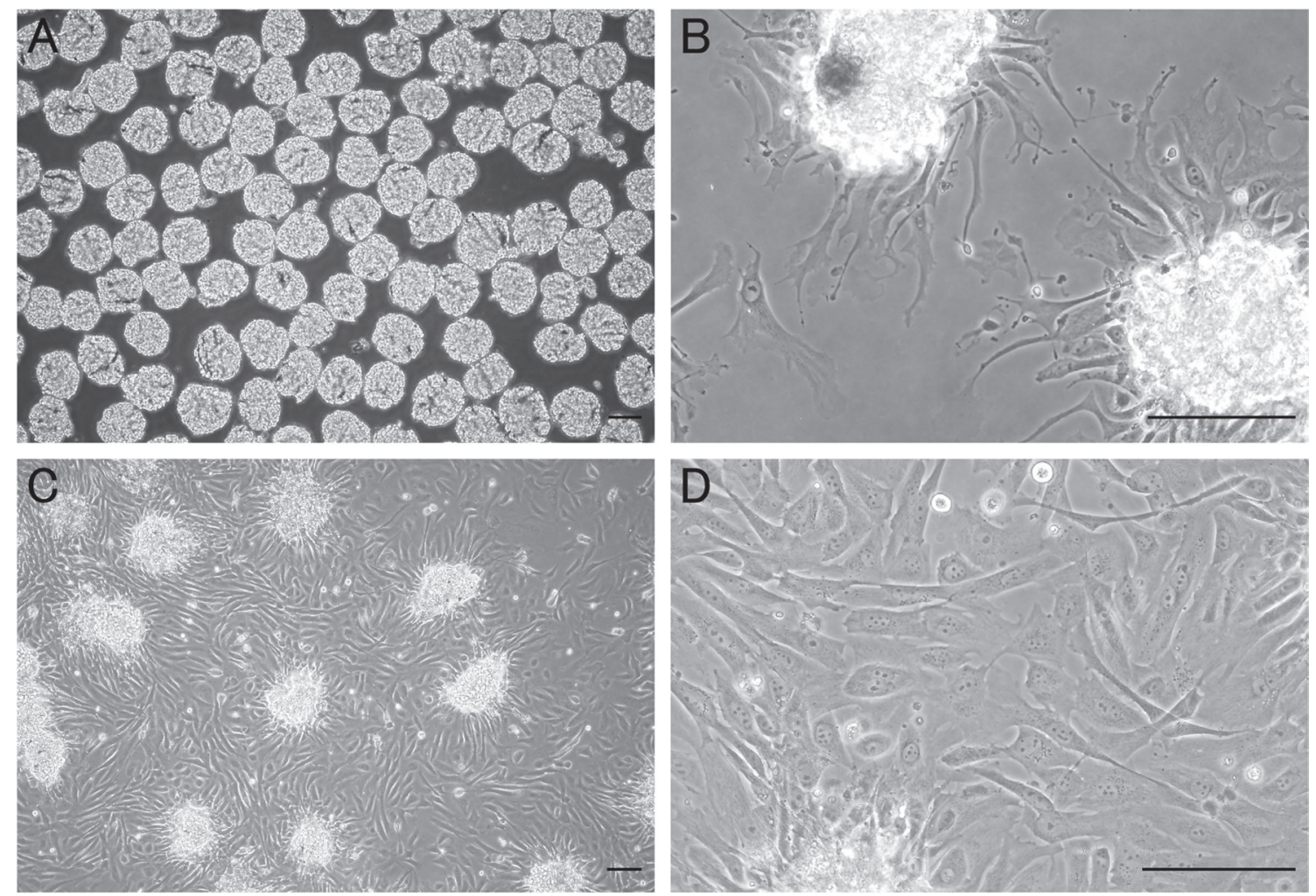

Fig. 2. Phase-contrast microscopy of isolated canine glomeruli and cellular growth of podocytes. Phase-contrast microscopy of isolated glomeruli from canine renal tissue (A) and their cellular outgrowths after 2 days (B) and 3 days (C and D) in culture.

*Isolated glomerulus, Bar $=100 \mu \mathrm{m}$.

ginal region. Notably, the podocytes also expressed $\mathrm{PLA}_{2} \mathrm{R}$ in the cytoplasm and marginal region (Fig. 3B). Expression of $\mathrm{PLA}_{2} \mathrm{R}$ and podocyte-specific proteins in the primary cultured podocytes was also confirmed by RT-PCR and WB for subcultured podocytes (Fig. 3C and 3D). Furthermore, a small number of fibroblast and tubular epithelial cells from contaminated blood vessels and tubules were observed. All examinations were performed using renal tissue from three different dogs, and they showed the same results (data not shown).

In this study, we revealed the expression of $\mathrm{PLA}_{2} \mathrm{R}$ in canine podocytes, and to our knowledge, this is the first report to demonstrate the expression of $\mathrm{PLA}_{2} \mathrm{R}$ in podocytes of non-primate mammals. Considering the high incidence of MN in dogs, this result represents an important new insight that dogs can potentially be used as an experimental or possibly spontaneous model for human idiopathic $\mathrm{MN}$ associated with $P_{2} A_{2} R$. The marginal localization of $P_{2} A_{2} R$ in canine cultured podocytes consistent with that of foot process-associated proteins (nephrin and podocin) is also an important finding supporting this possibility, because the binding of circulating antibodies against $\mathrm{PLA}_{2} \mathrm{R}$ on the basal surface of the podocyte foot processes is assumed to be the mechanism for subepithelial deposition of immune complexes which is a characteristic feature in idiopathic MN, as suggested by various reports using experimental rat models of MN [14] and human neonatal MN [6]. The expression of $\mathrm{PLA}_{2} \mathrm{R}$ in PECs is not reported in human, and it may be a characteristic feature of dogs.

In addition, we succeeded in establishing an effective primary culture method for canine podocytes by modifying an isolation method established for rats in a previous report [15]. A good preparation has previously been identified wherein $95 \%$ of the isolated tissue structures were glomeruli [18]; the samples obtained in the present study were assumed to be a good preparation according to this criterion. Moreover, we confirmed the reproducibility of the experiments using kidneys from three different dogs. Cultured podocytes derived from human, mice and rat glomeruli have been used in many studies aimed at elucidating their physiological and pathophysiological characteristics. The methods for primary podocyte culture are relatively convenient and well-established in rodents $[15,18]$. Also, primary cultured podocytes from isolated glomeruli are assumed to retain their in vivo phenotype.

Cultured canine podocytes in the present study expressed similar podocyte-specific markers as they did in in vivo studies $[12,16]$. The in vitro experiments using cultured podocytes may contribute to investigations into the function of $\mathrm{PLA}_{2} \mathrm{R}$ in podocytes and canine glomerular diseases, including MN. 
ACKNOWLEDGMENTS. This research was partially supported by a research project grant (2014k05) awarded by the Azabu University. Go Sugahara is a Research Fellow of the Japan Society for the Promotion of Science. We would like to express the deepest appreciation to Professor Dr. Yoko Fujii and Dr. Keisuke Sugimoto at the Laboratory of Veterinary Surgery I, Azabu University for their encouragement throughout this study.

\section{REFERENCES}

1. Beck, L. H. Jr., Bonegio, R. G., Lambeau, G., Beck, D. M., Powell, D. W., Cummins, T. D., Klein, J. B. and Salant, D. J. 2009. M-type phospholipase A2 receptor as target antigen in idiopathic membranous nephropathy. N. Engl. J. Med. 361: 11-21. [Medline] [CrossRef]

2. Beck, S., Beck, G., Ostendorf, T., Floege, J., Lambeau, G., Nevalainen, T., Radeke, H. H., Gurrieri, S., Haas, U., Thorwart, B., Pfeilschifter, J. and Kaszkin, M. 2006. Upregulation of group IB secreted phospholipase A(2) and its M-type receptor in rat ANTI-THY-1 glomerulonephritis. Kidney Int. 70: 1251-1260. [Medline] [CrossRef]

3. Boerries, M., Grahammer, F., Eiselein, S., Buck, M., Meyer, C., Goedel, M., Bechtel, W., Zschiedrich, S., Pfeifer, D., Laloë, D., Arrondel, C., Gonçalves, S., Krüger, M., Harvey, S. J., Busch, H., Dengjel, J. and Huber, T. B. 2013. Molecular fingerprinting of the podocyte reveals novel gene and protein regulatory networks. Kidney Int. 83: 1052-1064. [Medline] [CrossRef]

4. Cianciolo, R. E., Mohr, F. C., Aresu, L., Brown, C. A., James, C., Jansen, J. H., Spangler, W. L., van der Lugt, J. J., Kass, P. H., Brovida, C., Cowgill, L. D., Heiene, R., Polzin, D. J., Syme, H., Vaden, S. L., Dongen, A. M. and Lees, G. E. 2015. World Small Animal Veterinary Association Renal Pathology Initiative: Classification of Glomerular Diseases in Dogs. Vet. Pathol. 53: 113-135. [Medline]

5. Cupillard, L., Mulherkar, R., Gomez, N., Kadam, S., Valentin, E., Lazdunski, M. and Lambeau, G. 1999. Both group IB and group IIA secreted phospholipases A2 are natural ligands of the mouse 180-kDa M-type receptor. J. Biol. Chem. 274: 7043-7051. [Medline] [CrossRef]

6. Debiec, H., Guigonis, V., Mougenot, B., Decobert, F., Haymann, J. P., Bensman, A., Deschênes, G. and Ronco, P. M. 2002. Antenatal membranous glomerulonephritis due to anti-neutral endopeptidase antibodies. N. Engl. J. Med. 346: 2053-2060. [Medline] [CrossRef]

7. Hanasaki, K. and Arita, H. 2002. Phospholipase A2 receptor: a regulator of biological functions of secretory phospholipase A2. Prostaglandins Other Lipid Mediat. 68-69: 71-82. [Medline]
[CrossRef]

8. Hanasaki, K. 2004. Mammalian phospholipase A2: phospholipase A2 receptor. Biol. Pharm. Bull. 27: 1165-1167. [Medline] [CrossRef]

9. Hayashi, N., Akiyama, S., Okuyama, H., Matsui, Y., Adachi, H., Yamaya, H., Maruyama, S., Imai, E., Matsuo, S. and Yokoyama, H. 2015. Clinicopathological characteristics of M-type phospholipase A2 receptor (PLA2R)-related membranous nephropathy in Japanese. Clin. Exp. Nephrol. 19: 797-803. [Medline] [CrossRef]

10. Hofstra, J. M., Debiec, H., Short, C. D., Pellé, T., Kleta, R., Mathieson, P. W., Ronco, P., Brenchley, P. E. and Wetzels, J. F. 2012. Antiphospholipase A2 receptor antibody titer and subclass in idiopathic membranous nephropathy. J. Am. Soc. Nephrol. 23: 1735-1743. [Medline] [CrossRef]

11. Hoxha, E., Kneißler, U., Stege, G., Zahner, G., Thiele, I., Panzer, U., Harendza, S., Helmchen, U. M. and Stahl, R. A. 2012. Enhanced expression of the M-type phospholipase A2 receptor in glomeruli correlates with serum receptor antibodies in primary membranous nephropathy. Kidney Int. 82: 797-804. [Medline] [CrossRef]

12. Ichii, O., Yabuki, A., Sasaki, N., Otsuka, S., Ohta, H., Yamasaki, M., Takiguchi, M., Namiki, Y., Hashimoto, Y., Endoh, D. and Kon, Y. 2011. Pathological correlations between podocyte injuries and renal functions in canine and feline chronic kidney diseases. Histol. Histopathol. 26: 1243-1255. [Medline]

13. Jaenke, R. S. and Allen, T. A. 1986. Membranous nephropathy in the dog. Vet. Pathol. 23: 718-733. [Medline]

14. Jefferson, J. A., Pippin, J. W. and Shankland, S. J. 2010. Experimental models of membranous nephropathy. Drug Discov. Today Dis. Models 7: 27-33. [Medline] [CrossRef]

15. Katsuya, K., Yaoita, E., Yoshida, Y., Yamamoto, Y. and Yamamoto, T. 2006. An improved method for primary culture of rat podocytes. Kidney Int. 69: 2101-2106. [Medline] [CrossRef]

16. Kobayashi, R., Kamiie, J., Yasuno, K., Ogihara, K. and Shirota, K. 2011. Expression of nephrin, podocin, $\alpha$-actinin-4 and a3-integrin in canine renal glomeruli. J. Comp. Pathol. 145: 220-225. [Medline] [CrossRef]

17. Pan, Y., Wan, J., Liu, Y., Yang, Q., Liang, W., Singhal, P. C., Saleem, M. A. and Ding, G. 2014. sPLA2 IB induces human podocyte apoptosis via the M-type phospholipase A2 receptor. Sci. Rep. 4: 6660. [Medline] [CrossRef]

18. Shankland, S. J., Pippin, J. W., Reiser, J. and Mundel, P. 2007. Podocytes in culture: past, present, and future. Kidney Int. 72: 26-36. [Medline] [CrossRef]

19. Yaoita, E., Kurihara, H., Sakai, T., Ohshiro, K. and Yamamoto, T. 2001. Phenotypic modulation of parietal epithelial cells of Bowman's capsule in culture. Cell Tissue Res. 304: 339-349. [Medline] [CrossRef] 